\title{
Tracking performance of NPID controller for cutting force disturbance of ball screw drive
}

\author{
N. A. Anang1, L. Abdullah ${ }^{1 *}$, Z. Jamaludin', T.H. Chiew ${ }^{1}$, M. Maharof ${ }^{1}$, S.N.S. \\ Salim $^{2}$, Z. Retas ${ }^{1}$ and S.C.K. Junoh ${ }^{1}$ \\ ${ }^{1}$ Faculty of Manufacturing Engineering, Universiti Teknikal Malaysia Melaka, \\ 76100 Durian Tunggal, Melaka, Malaysia \\ "Email: lokman@utem.edu.my \\ Phone: +603316975; Fax: +6063316019 \\ ${ }^{2}$ Faculty of Engineering Technology, Technology Campus, \\ Universiti Teknikal Malaysia Melaka, \\ 76100 Durian Tunggal, Melaka, Malaysia
}

\begin{abstract}
The high demand in tracking performance is crucial in machine tools application. Therefore, the purpose of this paper is to design a Nonlinear PID (NPID) controller for improvement of tracking performance via cutting force. The method was then compared with another method which was conventional PID controller. The configuration included different cutting force disturbances of $1500 \mathrm{rpm}, 2500 \mathrm{rpm}$ and $3500 \mathrm{rpm}$. The parameters were set to $0.4 \mathrm{~Hz}$ and $0.7 \mathrm{~Hz}$ frequency for every $10 \mathrm{~mm}$ and $20 \mathrm{~mm}$ of amplitude, respectively. The investigation was centred on a comparative study of these two techniques which focused on X-axis of Googol Tech XY ball screw drive system. Results between the designed controllers were validated based on two types of errors; the maximum tracking error and root mean square error. Results showed that the NPID controller recorded better tracking performance compared to PID controller with an error reduction of about $33 \%$. In addition, the results proved that NPID controller is highly practical and suitable to be used for ball screw drive. The controller can be further improved with the implementation of observer such as disturbance observer to compensate the cutting forces.
\end{abstract}

Keywords: Ball screw drive system; tracking performance; NPID; cutting disturbance.

\section{INTRODUCTION}

Nowadays, demands on higher quality at lower cost of machine tools are increasing. Therefore, this phenomenon requires the machine tools to have high accuracy[1,2]. A few decades back showed tremendous researches done on the control strategy of machine tools, specifically in precision machining [3-7]. Other than that, Erkorkmaz K and Wong W[8] suggested a significant technique for virtual Computer Numerical Control (CNC) drive. Several controllers such as PID, cascade P/PI and an adaptive SMC validated the technique by simulation. The experimental validation was done by pole placement controller with Kalman filter and zero phase error tracking controller. The technique successfully predicted accurately both tracking and contour errors. For that reason, it is crucial for the machine tools to have good tracking performance to develop higher precision. Currently, many scholars have discussed their methods and approaches on 
improving the tracking performance[9-13]. However, the presence of disturbances such as cutting force, friction force, mechanical structure and work piece mass during machining affects the performance of the machine tools[14]. The interaction between the tool and the chip of material removed was said as the central to machining processes[15]. In a study by Salim et. al[16], NPID controllers with dead zone compensator were successfully applied to pneumatic actuator sensor where the resulting amplitude was less than 5\% compared to the disturbance signal amplitude. Several scholars have discussed the implementation of controller for disturbances rejection in machine tools[17, 18]. For cutting force purposes, cutting force during machining leads to poor precision and positioning, causing negative impacts towards machine tools. Scholars have done researches on this for many years[19-25] and one of the examples was by designing a robust and well-performed motion control design where a discrete time sliding mode controller was invented. The method has been popular, especially in stability control for its capability to cope with nonlinearities[26]. An integrated reaching law design method was successfully applied on XY machine tool and therefore, the compensation of the cutting force and robustness of the system were secured[27].

According to Altintas et. al[28], there are two prominent mechanical drives in the machine tool industry which are the ball screw and direct drives. Compared to rack and pinion, both drives promise high efficiency and precision in the control system industry. As the ball screw drive is the subject matter, ball screw drive moves in a linear motion from the rotary movement. Therefore, there are challenges for the drive to gain higher accuracy, especially at higher speed. The challenges include kinematics of the rolling balls and dynamic behaviour[29]. However, the drive is capable of increasing the accuracy of the machine tool. This is proven as the ball screw can position the slides of a machine tool to eliminate gaps that exist in the machine tool for higher accuracy[30]. As time goes by, many researches in the mechanism and development of drives in machine tools have been carried out by several scholars[31-37]. There are many controllers designed for better tracking performance of ball screw drive[38, 39]. However, there is still a lack on improving the cutting force disturbance for a wide range of parameters, specifically for ball screw drive. The objective of this research is to design a nonlinear PID controller for cutting force compensation to improve the tracking performance of ball screw drive at $1500 \mathrm{rpm}, 2500 \mathrm{rpm}$ and $3500 \mathrm{rpm}$ of spindle speed rotations.

\section{METHODS AND MATERIALS}

\section{Experimental Setup}

The current research focused on designing two controllers which are NPID and PID controllers. A Frequency Response Function (FRF) of the system was obtained for the modelling process based on system identification. Next, a H1 estimator estimated the FRF [40].The generated transfer function was represented as a second order model with a time delay of 0.0012 seconds. MATLAB toolbox of 'fdident' generated a second order model as the system modelling[41, 42].With that, the transfer function that represented the model of Googol Tech XY ball screw drive system is shown in Eq. (1):

$$
G_{m}=\frac{78020}{s^{2}+163 s+193.3}
$$

Figure 1 shows the important components required for the experimental setup that consisted of a computer, a Digital Signal Processing (DSP), an amplifier and an XY table 
ball screw drive system. The computer helped the interaction between the user and real plant. The MATLAB and ControlDesk software were installed in the computer. The interaction in the computer was sent to the DSP that played as Input Output (I/O) interface before sending the information to the servo amplifier that was connected with the XY ball screw drive system. The Googol Tech XY ball screw drive system is shown in Figure 2.

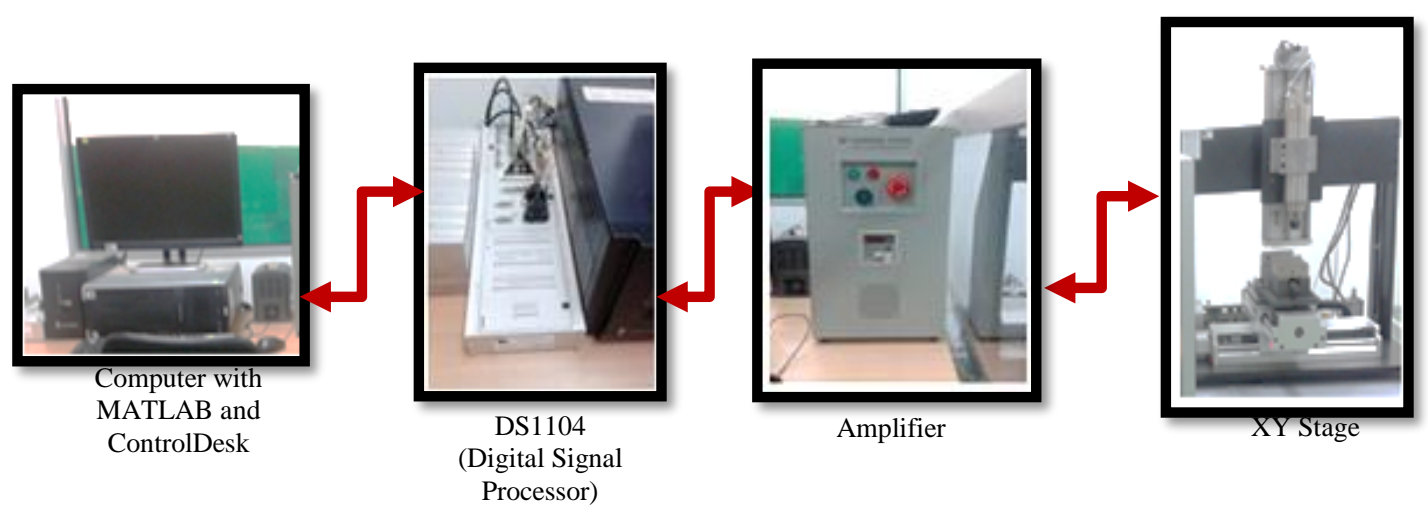

Figure 1. Schematic diagram of experimental setup.

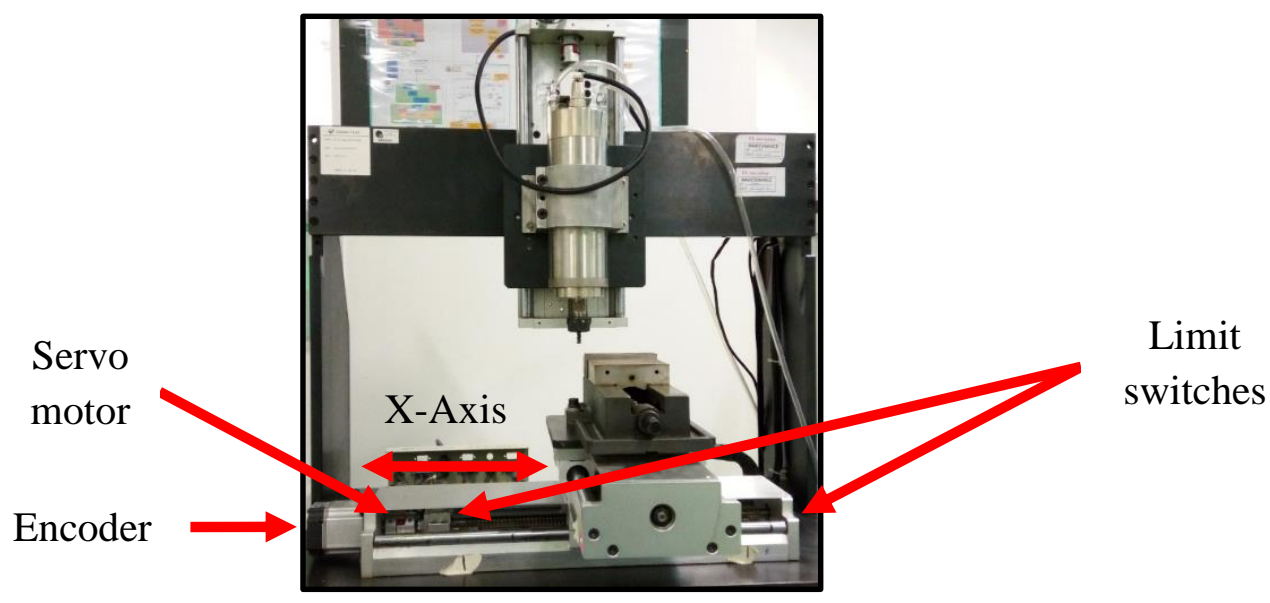

Figure 2. XY stage.

\section{Controller Design}

The controller design for this study included open loop, stability and sensitivity. The first controller was PID controller. Besides that, the controller was the first step in designing NPID controller. Eq. (2) shows the general transfer function of PID[43-45]:

$$
G_{c}(s)=K_{P}+\frac{K_{I}}{s}+K_{D} s
$$

where $K_{p}, K_{I}$ and $K_{D}$ are the proportional, integral and derivative component of the controller, respectively, and these parameters were defined based on a method called conventional loop shaping[46]. Figure 3 shows the control structure of the PID controller. 


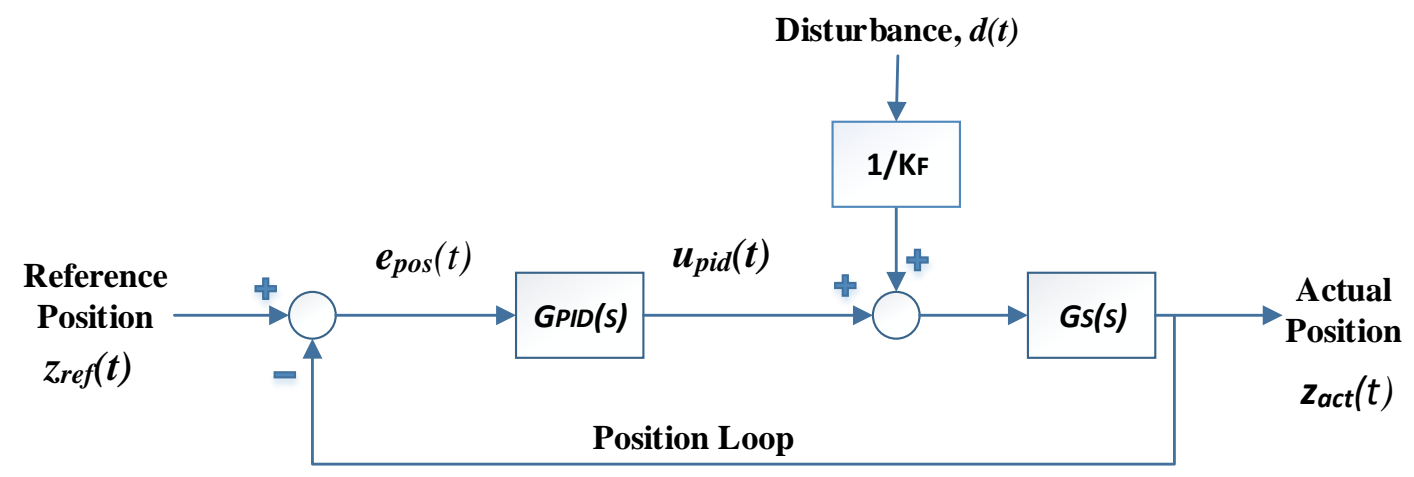

Figure 3. PID control scheme.

Therefore, the modelling for the PID controller is as shown below:

$$
\begin{aligned}
\text { Open Loop, OLPID } & =\frac{\text { Actual Position }}{\text { Position Tracking Error }}=G_{P I D}(s)+G_{S}(s) \\
\text { Closed Loop, CLPID } & =\frac{\text { Actual Position }}{\text { Reference Position }}=\frac{G_{P I D}(s) \times G_{S}(s)}{1+G_{P I D}(s)+G_{s}(s)} \\
\text { Sensitivity, } \mathrm{S}_{\mathrm{PID}} & =1-\mathrm{CL}_{\mathrm{PID}}=\frac{1}{1+G_{P I D}(s) \times G_{S}(s)}
\end{aligned}
$$

With that, the transfer function of PID controller is as given in Eq. (6):

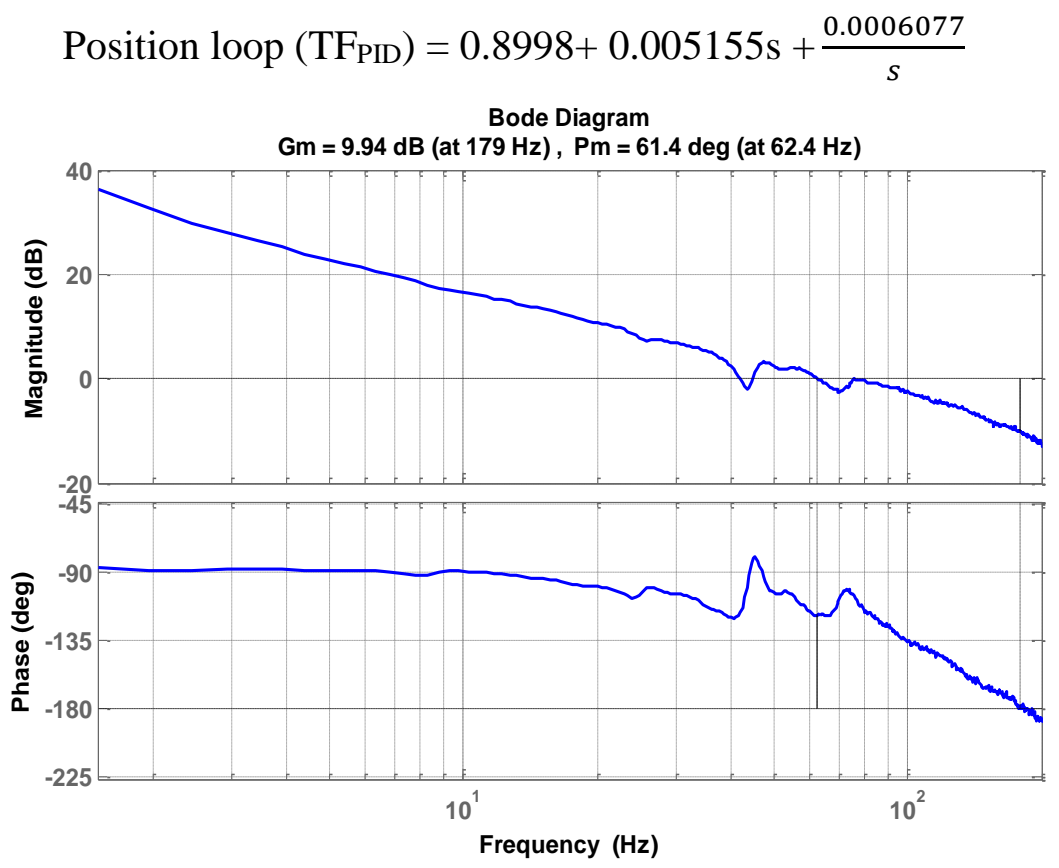

Figure 4. Gain margin and phase margin.

The gain margin and phase margin were identified from the position of the open loop transfer function shown in Figure 4. The figure shows that the designed controller has $9.94 \mathrm{~dB}$ for the gain margin and $61.4^{0}$ for phase margin. This follows the rule of thumb 
of the gain and phase margin which must be larger than $5 \mathrm{~dB}$ and $40^{\circ}$, respectively[47]. Next, the system was analysed based on stability. The stability of the system was determined by the Nyquist plot as shown in Figure 5. The system was stable because the plot did not encircle the coordinate $(-1,0)$.

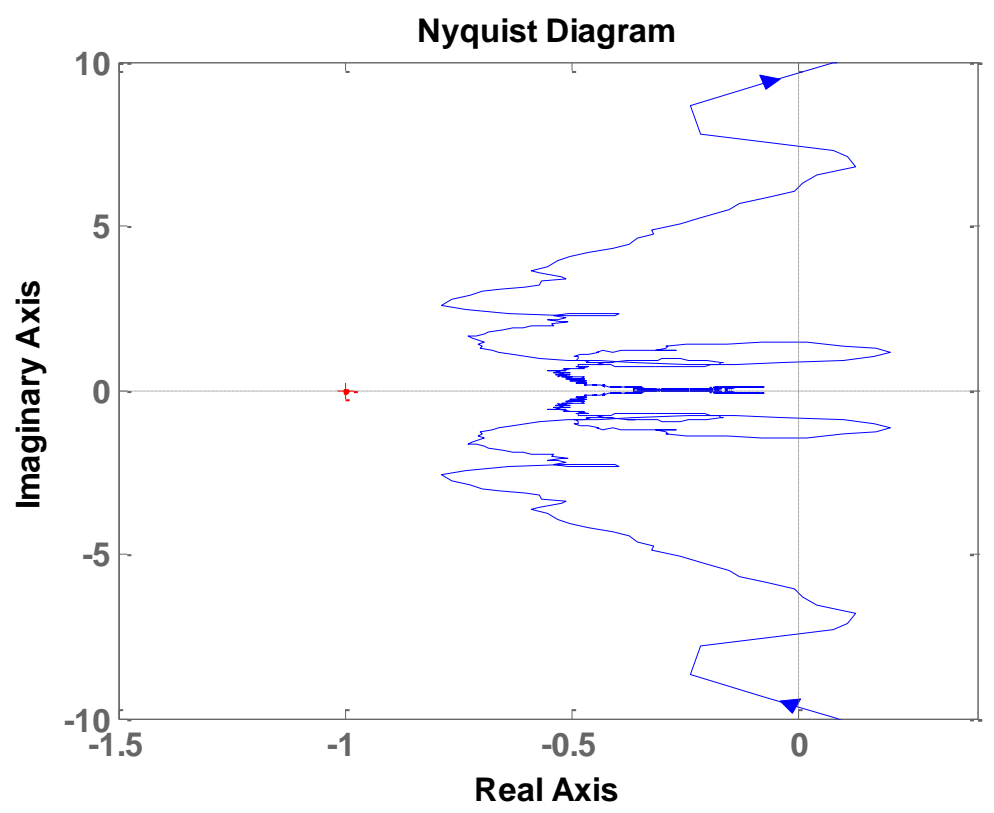

Figure 5. Nyquist plot for system stability.

Figure 6 shows the sensitivity of the system based on $-3 \mathrm{~dB}$ crossing of the magnitude plot of the sensitivity function. The bandwidth of the system was important as the bandwidth showed the capability of the system to adapt until $44.4 \mathrm{~Hz}$. The maximum peak sensitivity of the system must be less than $6 \mathrm{~dB}$ to remain a good transient response [39]. Therefore, Figure 7 shows the maximum peak sensitivity of 5.12dB.

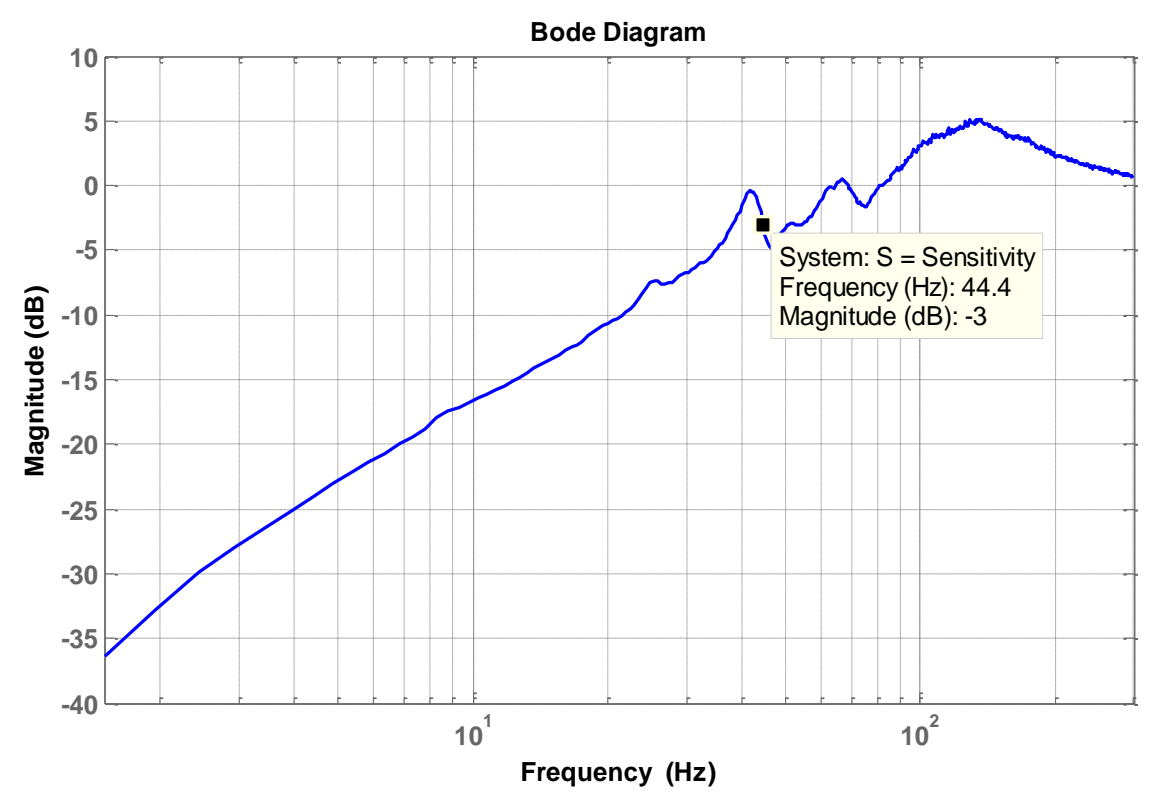

Figure 6. Bandwidth of the system 


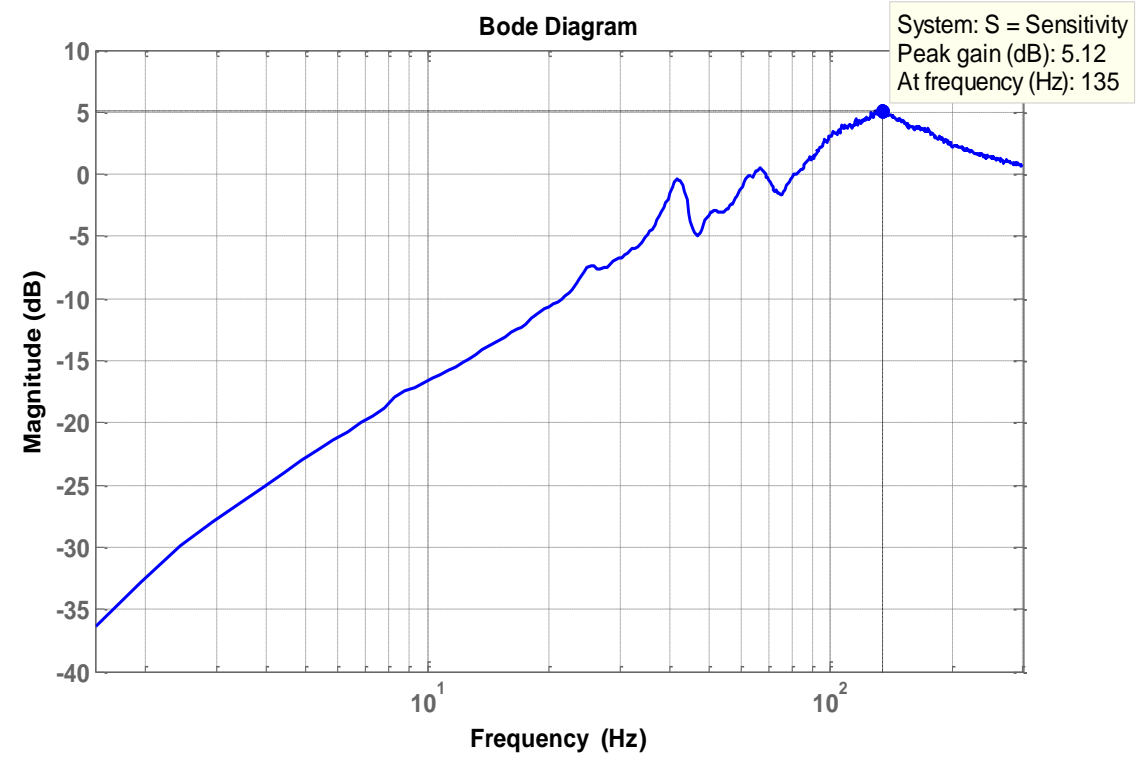

Figure 7. Maximum peak sensitivity.

In contrast, the proposed method is the advancement of the conventional PID controller where the nonlinear function was located at the front. Unlike the PID controller, NPID has two additional parameters beside $K_{p} K_{I}$ and $K_{D}$. Both $K O$ and $e_{\max }$ are the rate of variation for the nonlinear gain and the maximum value of error, respectively, noted as the N-function in Figure 8.

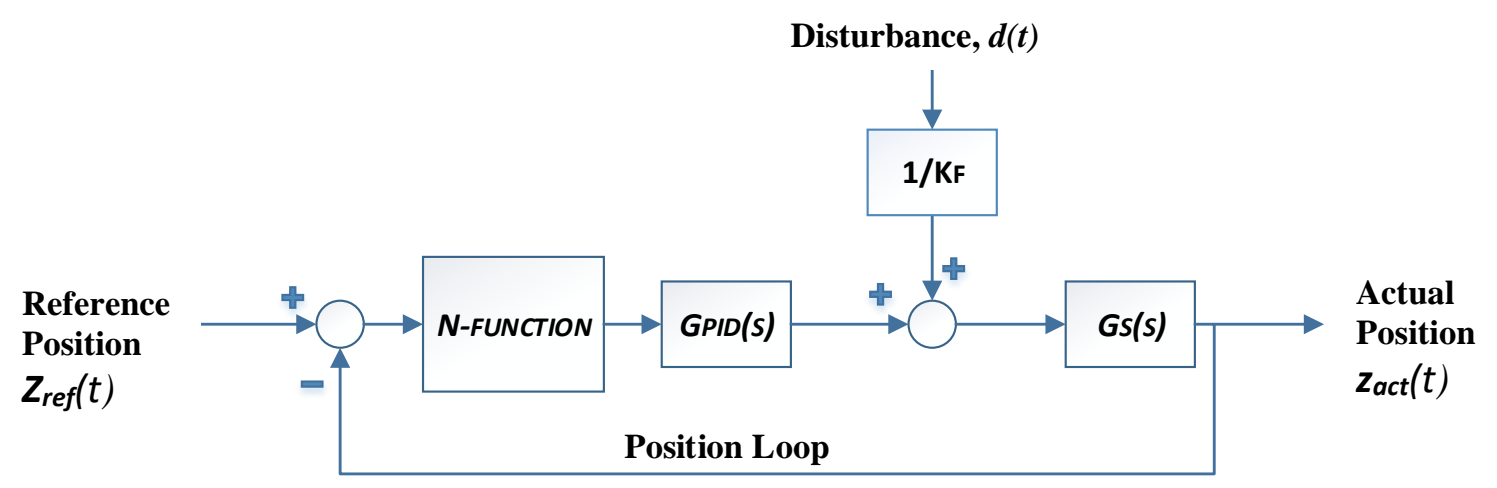

Figure 8. NPID control scheme.

Values of $K O$ and $e_{\max }$ were obtained based on the nonlinear gain, Ke using the heuristic method based on a U-shaped Popov plot[38]. Figure 9 shows the Popov plot obtained. From the figure, we can find the crossing point at $(-0.3071, \mathrm{j} 0)$. The point was then used to calculate the $\mathrm{K} e_{\max }$ where the formula is given in Eq. (7):

$$
\mathrm{K}\left(e_{\max }\right)=\frac{1}{\left|G_{\text {openloop }} j w\right|}
$$

Therefore, the $\mathrm{K} e_{\max }$ is 3.2563. Next, the $K O$ and $e_{\max }$ were tuned in order to calculate $\mathrm{Ke}$ as shown in Eq. (8): 


$$
\mathrm{K} e=\frac{\exp (K O \times e)+\exp (-K O \times e)}{2}
$$

The rule is $\mathrm{Ke}$ must be less or the same as $\mathrm{Ke} e_{\max }$. After several attempts, the chosen $\mathrm{KO}$ and $e_{\max }$ were 6 and 0.3, respectively, which resulted in 3.1075 for Ke.

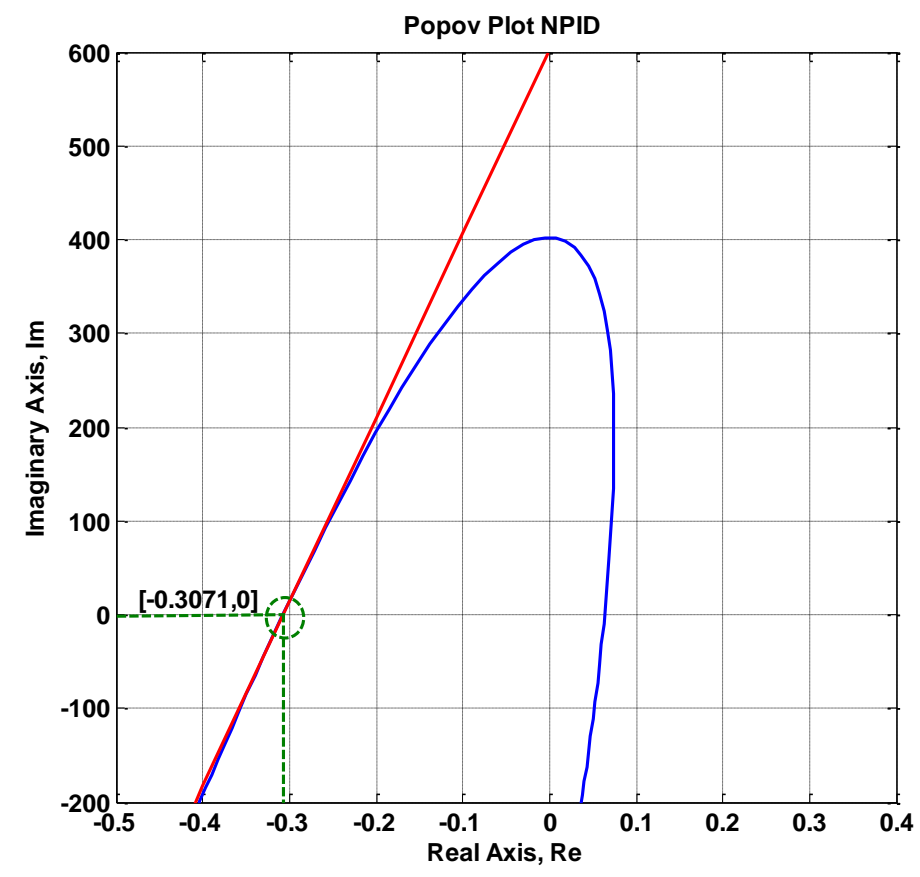

Figure 9. Popov plot of NPID.

\section{RESULTS AND DISCUSSION}

In this section, the tracking performance of XYZ table ball screw drive system based on the NPID controller is presented in comparison with the PID controller. The performances were compared with and without the cutting disturbances of 1500rpm, 2500rpm and $3500 \mathrm{rpm}$. The frequency was set at $0.4 \mathrm{~Hz}$ and $0.7 \mathrm{~Hz}$ for every $10 \mathrm{~mm}$ and $20 \mathrm{~mm}$ amplitude, respectively, where sinusoidal input was implemented.

\section{Tracking Performance Analyses}

Figure 10 shows the performance when $0.4 \mathrm{~Hz}$ of $10 \mathrm{~mm}$ amplitude was used during 1500 rpm cutting condition. Based on the figure, the cutting force disturbance was injected to the system for a duration of 10 seconds. The comparison for NPID and PID controllers positively showed that the NPID controller had a better tracking performance compared to the PID controller[16] as the maximum tracking error for both controllers showed that NPID had a lower maximum tracking error compared to the PID controller. Table 1 and Table 2 show the maximum tracking error of the existence and absence of cutting force, respectively. As seen below, the results were concluded into three stages. Firstly, the NPID controller showed lower maximum tracking error compared to the PID controller, regardless of the existence of disturbance, frequency and amplitude. Secondly, the maximum tracking error was shown to be in decrement when higher cutting disturbance was injected. This is because eof the feed per tooth, $f$ is inversely proportional to the spindle speed rotations of the cutter, $N$ which supports the statement of the higher the 
spindle speed rotations, the lower the surface contacted to the workpiece. Lastly, the maximum error increases when higher frequency is used. This phenomenon is due to processing the time factor [48]. According to the scholar, the controllers have more time to response at low frequency compared to high frequency.

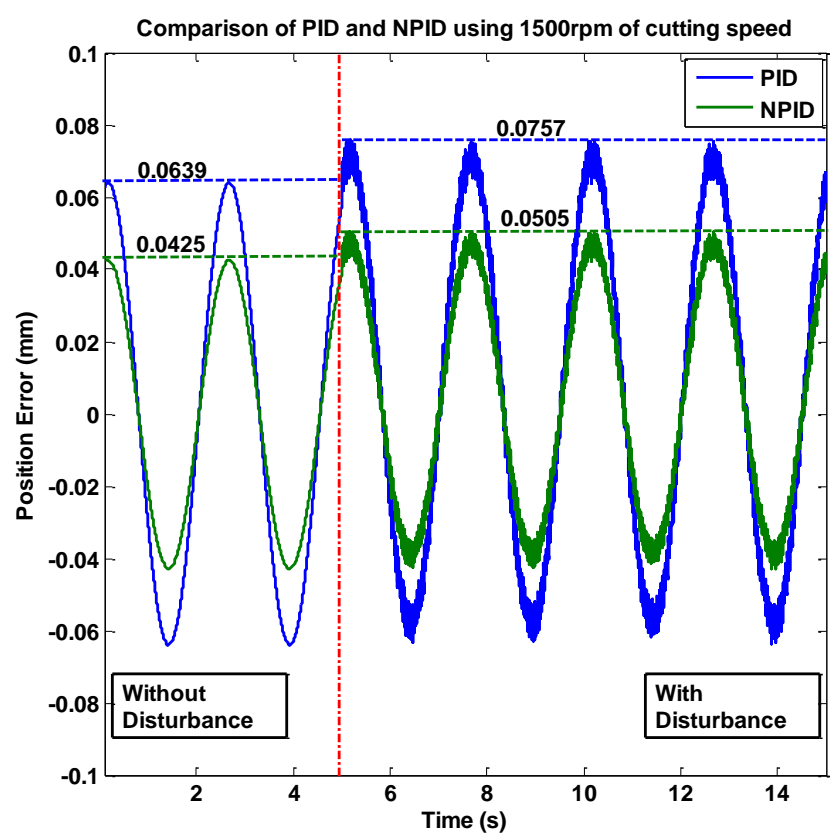

Figure 10. Tracking performance of $0.4 \mathrm{~Hz}$ for $10 \mathrm{~mm}$ amplitude.

Table 1. Maximum tracking error without disturbance.

\begin{tabular}{cccc}
\hline Frequency $(\mathrm{Hz})$ & Amplitude $(\mathrm{mm})$ & \multicolumn{2}{c}{ Maximum tracking error $(\mathrm{mm})$} \\
\hline & & PID & NPID \\
\hline 0.4 & 10 & 0.0639 & 0.0425 \\
& 20 & 0.1048 & 0.0694 \\
0.7 & 10 & 0.1273 & 0.0842 \\
& 20 & 0.2086 & 0.1369 \\
\hline
\end{tabular}

Table 2. Maximum tracking error with disturbance.

\begin{tabular}{ccccc}
\hline Frequency $(\mathrm{Hz})$ & Amplitude $(\mathrm{mm})$ & Spindle Speed(rpm) & \multicolumn{2}{c}{ Max. Tracking Error $(\mathrm{mm})$} \\
\cline { 3 - 5 } & & & PID & NPID \\
\hline 0.4 & 10 & 1500 & 0.0757 & 0.0507 \\
& & 2500 & 0.0746 & 0.0500 \\
0.4 & \multirow{2}{*}{20} & 3500 & 0.0727 & 0.0484 \\
& & 1500 & 0.1172 & 0.0777 \\
0.7 & \multirow{2}{*}{10} & 2500 & 0.1155 & 0.0762 \\
& & 3500 & 0.1141 & 0.0761 \\
0.7 & \multirow{2}{*}{20} & 1500 & 0.1398 & 0.0924 \\
& & 2500 & 0.1386 & 0.0918 \\
& & 1500 & 0.1367 & 0.0906 \\
& & 2500 & 0.2217 & 0.1459 \\
& & 3500 & 0.2197 & 0.1449 \\
& & & 0.2193 & 0.1444 \\
\hline
\end{tabular}




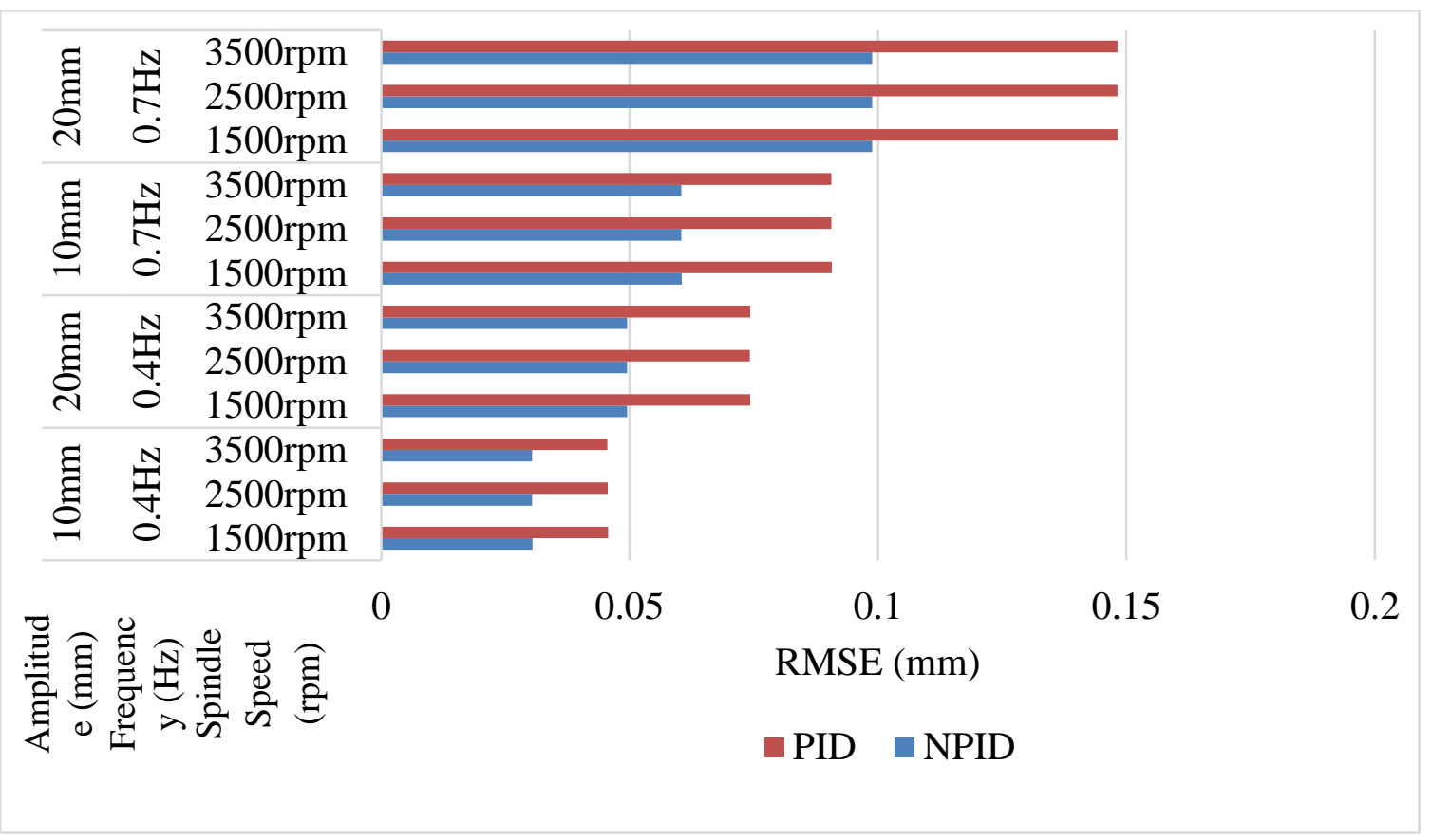

Figure 11. RMSE with cutting force disturbance.

Table 3 shows the tabulated error reduction produced. Overall, the error reductions between the designed controllers were up to $34 \%$. Furthermore, based on the table, there are no specific trends in the error reduction at varying values of spindle speed.

Table 3. Error reduction between NPID and PID controllers.

\begin{tabular}{cccc}
\hline $\begin{array}{c}\text { Frequency } \\
(\mathrm{Hz})\end{array}$ & $\begin{array}{c}\text { Amplitude } \\
(\mathrm{mm})\end{array}$ & $\begin{array}{c}\text { Spindle Speed } \\
(\mathrm{rpm})\end{array}$ & $\begin{array}{c}\text { Error Reduction (\%) between } \\
\text { NPID and PID }\end{array}$ \\
\hline 0.4 & 10 & 1500 & 33.03 \\
& & 2500 & 32.98 \\
0.4 & 20 & 3500 & 33.43 \\
& & 1500 & 33.70 \\
0.7 & 2500 & 34.03 \\
& \multirow{2}{*}{10} & 3500 & 33.30 \\
0.7 & 1500 & 33.91 \\
& \multirow{2}{*}{20} & 2500 & 33.77 \\
& & 3500 & 33.72 \\
& & 1500 & 34.19 \\
& & 2500 & 34.05 \\
\hline
\end{tabular}

Next, comparisons of both controllers were analysed based on the error reduction. This approach was calculated based on the RMSE of both controllers as given in Eq. (9):

$$
\left|\frac{\text { RMSE NPID-RMSE PID }}{\text { RMSE PID }}\right| \times 100 \%
$$


As error reduction was formulated using RMSE, Figure 11 shows the comparisons of RMSE for both controllers with cutting force disturbance. The figure clearly shows that higher RMSE is executed as higher frequency and amplitude are applied. The values were then calculated for the error reduction approach.

\section{CONCLUSIONS}

In conclusion, the NPID controller was implemented at the XY table ball screw drive system. The controller was designed according to the configuration as follows: The disturbances were $1500 \mathrm{rpm}, 2500 \mathrm{rpm}$ and $3500 \mathrm{rpm}$ of cutting force. The input applied was sinusoidal with frequency of $0.4 \mathrm{~Hz}$ and $0.7 \mathrm{~Hz}$ for every $10 \mathrm{~mm}$ and $20 \mathrm{~mm}$ of amplitude, respectively. The results were then compared with a conventional controller namely the PID controller. The method of the NPID controller had a lower maximum tracking error, with and without disturbance, RMSE and successfully compensated the cutting force disturbance up to $34 \%$. Therefore, this research successfully proved that the method provides a better tracking performance compared to the PID controller. However, improvement of the proposed method is highly recommended in order to increase the error reduction between controllers specifically for the XY table ball screw drive system. The implementation of an observer such as disturbance observer is expected to improve the performance of the controller as the element helps the controller to adapt with varying parameters and conditions.

\section{ACKNOWLEDGEMENTS}

The authors would like to acknowledge the financial support by Universiti Teknikal Malaysia Melaka (UTeM) under the scholarship of 'Skim Zamalah UTeM', short term grant scheme (PJP) Universiti Teknikal Malaysia Melaka with reference number PJP/2014/FKPPROTOTAIP/S01379 and Ministry of Higher Education for FRGS grant with reference number FRGS/1/2016/TK03/FKP-AMC/F00320.

\section{REFERENCES}

[1] Jamaludin J, Jamaludin Z, Chiew T, Abdullah L. Design and Analysis of Disturbance Force Observer for Machine Tools Application. Applied Mechanics and Materials: Trans Tech Publ; 2015. p. 148-52.

[2] Moriwaki T. Multi-functional machine tool. CIRP Annals-Manufacturing Technology. 2008;57:736-49.

[3] Aggogeri F, Borboni A, Faglia R, Merlo A, Pellegrini N. A Kinematic Model to Compensate the Structural Deformations in Machine Tools Using Fiber Bragg Grating (FBG) Sensors. Applied Sciences. 2017;7:114.

[4] Villegas FJ, Hecker RL, Peña ME, Vicente DA, Flores GM. Modeling of a linear motor feed drive including pre-rolling friction and aperiodic cogging and ripple. The International Journal of Advanced Manufacturing Technology. 2014;73:26777.

[5] Pengbing Z, Yaoyao S. Adaptive sliding mode control of the A-axis used for blisk manufacturing. Chinese Journal of Aeronautics. 2014;27:708-15.

[6] Strakos P, Karasek T. Adaptive model predictive control as a prospect for control of machine tools with significant flexibility. AIP Conference Proceedings: AIP Publishing; 2015. p. 830006. 
[7] Nuella I, Cheng C, Chiu M-S. Adaptive PID controller design for nonlinear systems. Industrial and Engineering Chemistry Research. 2009;48:4877-83.

[8] Erkorkmaz K, Wong W. Rapid identification technique for virtual CNC drives. International Journal of Machine Tools and Manufacture. 2007;47:1381-92.

[9] Xi X-C, Zhao W-S, Poo A-N. Improving CNC contouring accuracy by robust digital integral sliding mode control. International Journal of Machine Tools and Manufacture. 2015;88:51-61.

[10] Dong R, Pedrycz W. Approximation grid evaluation-based PID control in cascade with nonlinear gain. Journal of the Franklin Institute. 2015;352:4279-96.

[11] Singh C. Genetic Algorithms Based PID controller Design. International Journal of Enginering Development and Research. 2015;3:2-5.

[12] Vicente DA, Hecker RL, Villegas FJ, Flores GM. Modeling and vibration mode analysis of a ball screw drive. The International Journal of Advanced Manufacturing Technology. 2012;58:257-65.

[13] Bakhtiari-Nejad F, Nazemizadeh M, Arjmand H. Tracking control of an underactuated gantry crane using an optimal feedback controller. International Journal of Automotive and Mechanical Engineering. 2013;7:830.

[14] Peng L, Mai J, Jiang T, Lai X, Lin Z. Experimental investigation of tensile properties of SS316L and fabrication of micro/mesochannel features by electricalassisted embossing process. Journal of Micro and Nano-Manufacturing. 2014;2:021002.

[15] Ghani SAC, Cheng K, Minton T. Back chip temperature in environmentally conscious turning with conventional and internally cooled cutting tools. Journal of Mechanical Engineering and Sciences. 2013;4:356-72.

[16] Salim SNS, Ismail Z, Rahmat M, Faudzi A, Sunar N, Samsudin SI. Tracking performance and disturbance rejection of pneumatic actuator system. Control Conference (ASCC), 2013 9th Asian: IEEE; 2013. p. 1-6.

[17] Abdullah L, Jamaludin Z, Ahsan Q, Jamaludin J, Rafan NA, Chiew T, et al. Evaluation on tracking performance of PID, gain scheduling and classical cascade P/PI controller on XY table ballscrew drive system. World Applied Sciences Journal. 2013;21:1-10.

[18] Ariffin M, Kamaluddin R, Tang S, Mohamed SB. Analysis of Automated G-Clip Machine Processes and Substation Process with Simulation by Using CAD Software. Materials Science Forum: Trans Tech Publ; 2014. p. 28-36.

[19] Razak N, Rahman M, Kadirgama K. Cutting force and chip formation in end milling operation when machining nickel-based superalloy, Hastelloy C-2000. Journal of Mechanical Engineering and Sciences. 2017;11:2539-51.

[20] Maharof M, Jamaludin Z, Minhat M, Ito T. Review on Cutting Force Compensation Techniques for Machine Tools Application. Applied Mechanics and Materials: Trans Tech Publ; 2015. p. 250-4.

[21] Pitstra W, Pieper J. Controller designs for constant cutting force turning machine control. ISA transactions. 2000;39:191-203.

[22] Pitstra W, Pieper J. Control of a turning machine for constant cutting force. American Control Conference, 1997 Proceedings of the 1997: IEEE; 1997. p. 3669-73.

[23] Yang M, Park H. The prediction of cutting force in ball-end milling. International Journal of Machine Tools and Manufacture. 1991;31:45-54. 
[24] Kamalzadeh A, Gordon DJ, Erkorkmaz K. Robust compensation of elastic deformations in ball screw drives. International Journal of Machine Tools and Manufacture. 2010;50:559-74.

[25] Najiha M, Rahman M, Kamal M, Yusoff A, Kadirgama K. Minimum quantity lubricant flow analysis in end milling processes: A computational fluid dynamics approach. Journal of Mechanical Engineering and Sciences. 2012;3:340-5.

[26] Jafari M, Mirzaei M, Mirzaeinejad H. Optimal nonlinear control of vehicle braking torques to generate practical stabilizing yaw moments. International Journal of Automotive and Mechanical Engineering. 2015;11:2639.

[27] Wang J, Van Brussel H, Swevers J. Positioning and tracking control of an xy table with sliding mode control. IFAC Proceedings Volumes. 2003;36:157-62.

[28] Altintas Y, Verl A, Brecher C, Uriarte L, Pritschow G. Machine tool feed drives. CIRP Annals-Manufacturing Technology. 2011;60:779-96.

[29] Azkoita J, Zulaika J, Gonzalez R. High Speed Machining: A Challenge for Ball Screw Drives. Retrieved from file:///E:/calibration/Azkoitia_josemiguel_revised pdf.

[30] Bediaga I, Munoa J, Hernández J, De Lacalle LL. An automatic spindle speed selection strategy to obtain stability in high-speed milling. International Journal of Machine Tools and Manufacture. 2009;49:384-94.

[31] Zhou C-G, Feng H-T, Chen Z-T, Ou Y. Correlation between preload and no-load drag torque of ball screws. International Journal of Machine Tools and Manufacture. 2016;102:35-40.

[32] Caracciolo R, Richiedei D. Optimal design of ball-screw driven servomechanisms through an integrated mechatronic approach. Mechatronics. 2014;24:819-32.

[33] Kim M-S, Chung S-C. Integrated design methodology of ball-screw driven servomechanisms with discrete controllers. Part I: Modelling and performance analysis. Mechatronics. 2006;16:491-502.

[34] Zhu S, Ding G, Qin S, Lei J, Zhuang L, Yan K. Integrated geometric error modeling, identification and compensation of $\mathrm{CNC}$ machine tools. International Journal of Machine Tools and Manufacture. 2012;52:24-9.

[35] Ramesh R, Mannan M, Poo A. Tracking and contour error control in CNC servo systems. International Journal of Machine Tools and Manufacture. 2005;45:30126.

[36] Wei CC, Lin JF. Kinematic analysis of the ball screw mechanism considering variable contact angles and elastic deformations. Journal of Mechanical Design. 2003;125:717-33.

[37] Mori M, Fujishima M, Inamasu Y, Oda Y. A study on energy efficiency improvement for machine tools. CIRP Annals-Manufacturing Technology. 2011;60:145-8.

[38] Abdullah L, Jamaludin Z, Rafan N, Jamaludin J, Chiew T. Assessment on tracking error performance of Cascade P/PI, NPID and N-Cascade controller for precise positioning of xy table ballscrew drive system. IOP Conference Series: Materials Science and Engineering: IOP Publishing; 2013. p. 012010.

[39] Retas Z, Abdullah L, Salim S, Jamaludin Z, Anang N. Tracking error compensation of XY table ball screw driven system using cascade fuzzy P+PI. International Review Automatic Control. 2016;9:324-33.

[40] Pintelon R, Schoukens J. System identification: a frequency domain approach: John Wiley \& Sons; 2012. 
[41] Chiew T, Jamaludin Z, Hashim AB, Rafan N, Abdullah L. Identification of friction models for precise positioning system in machine tools. Procedia Engineering. 2013;53:569-78.

[42] Jamaludin Z, Van Brussel H, Swevers J. Tracking performances of cascade and sliding mode controllers with application to a XY milling table. Proceedings of ISMA2006. 2006;81.

[43] Chiew T, Jamaludin Z, Hashim AB, Leo K, Abdullah L, Rafan N. Analysis of tracking performance in machine tools for disturbance forces compensation using sliding mode control and PID controller. International Journal of Mechanical \& Mechatronics Engineering. 2012;12:34-40.

[44] Jamaludin J. Disturbance rejection using disturbance force observer for xyz positioning table: Universiti Teknikal Malaysia Melaka; 2015.

[45] Maharof M, Jamaludin Z, Minhat M, Anang N, Chiew T, Jamaludin J. Design and analysis of disturbance force observer for milling cutting force compensation. International Journal of Mechanical Mechatronics Engineering. 2017;17:53-62.

[46] Padhan DG, Majhi S. Synthesis of PID tuning for a new parallel cascade control structure. IFAC Proceedings Volumes. 2012;45:566-71.

[47] Chiew TH. N-PID controller with feedforward of generalized maxwell-slip and static friction model for for friction compensation in machine tools: Universiti Teknikal Malaysia Melaka; 2014.

[48] Abdullah L. A new control strategy for cutting force disturbance compensation for XY table ball screw driven system: (Manufacturing Engineering)-Universiti Teknikal Malaysia Melaka; 2014. 